Check for updates

Cite this: Chem. Commun., 2021, 57,10608

Received 29th July 2021,

Accepted 20th September 2021

DOI: $10.1039 / \mathrm{d} 1 \mathrm{cc} 04122 \mathrm{c}$

rsc.li/chemcomm

\section{Azulene-based fluorescent chemosensor for adenosine diphosphate $\dagger$}

\author{
Carlos M. López-Alled, (D) ab Sang Jun Park, ${ }^{c}$ Dong Joon Lee, ${ }^{c}$ Lloyd C. Murfin, (D) ${ }^{a}$ \\ Gabriele Kociok-Köhn, (iD) d Jodie L. Hann, (D) a Jannis Wenk, (D) *be \\ Tony D. James, (D) *abf Hwan Myung Kim (D) *c and Simon E. Lewis (ID *ab
}

AzuFluor $^{\circledR}$ 435-DPA-Zn, an azulene fluorophore bearing two zinc(II)dipicolylamine receptor motifs, exhibits fluorescence enhancement in the presence of adenosine diphosphate. Selectivity for ADP over ATP, AMP and PPi results from appropriate positioning of the receptor motifs, since an isomeric sensor cannot discriminate between ADP and ATP.

As well as being the central constituent of DNA and RNA, the naturally occurring nucleotides (in various phosphorylation states) are crucial in numerous other biological contexts, for example as chemical messengers, as coenzymes, and in energy storage and transfer. Accordingly, there is sustained interest in methods for the selective detection and quantitation of the various nucleotides, to enable the elucidation of their diverse biological roles. Use of fluorescent chemosensors is an attractive technique for this purpose, ${ }^{1}$ since they typically have the advantages of high selectivity, sensitivity, rapid response, and reversibility, allowing nucleotide flux to be monitored over time. Adenosine triphosphate (ATP) is a nucleotide of particular importance for study owing to its role as Nature's universal energy carrier. ${ }^{2}$ The release of chemical energy through ATP hydrolysis entails formation of adenosine diphosphate (ADP), so co-occurrence of these two analytes is a common scenario,

\footnotetext{
${ }^{a}$ Department of Chemistry, University of Bath, Bath, BA2 7AY, UK.

E-mail:T.D.James@bath.ac.uk, S.E.Lewis@bath.ac.uk

${ }^{b}$ Centre for Sustainable Circular Technologies, University of Bath, Bath, BA2 7AY, UK. E-mail: J.H.Wenk@bath.ac.uk

${ }^{c}$ Department of Energy Systems Research, Ajou University, Suwon 443-749, South Korea.E-mail: kimhm@ajou.ac.kr

${ }^{d}$ Material and Chemical Characterisation Facility $\left(M C^{2}\right)$, University of Bath, Bath, $B A 27 A Y, U K$

${ }^{e}$ Department of Chemical Engineering, University of Bath, Bath, BA2 7AY, UK

${ }^{f}$ School of Chemistry and Chemical Engineering, Henan Normal University, Xinxiang 453007, China

$\dagger$ Electronic supplementary information (ESI) available: Synthetic details, fluorescence data, NMR spectra. All data generated in this project are available in the ESI. CCDC 2095982 and 2095983. For ESI and crystallographic data in CIF or other electronic format see DOI: 10.1039/d1 cc04122c
}

and hence the selectivity for one analyte over the other is an important parameter for any fluorescent probe.

Amongst various receptor motifs for nucleotides that have been reported, Zn(II)-dipicolylamine (Zn-DPA) complexes have been employed in numerous sensors as they typically exhibit high selectivity for phosphates over other anions (Fig. 1). ${ }^{3}$ However, the selectivity profile for such sensors can vary significantly, depending on the nature of the fluorophore and scaffold to which the Zn-DPA recognition unit(s) are appended, as well as their position and orientation. Thus, for some Zn-DPA-based sensors, pyrophosphate anion (PPi) induces a greater fluorescence response than any nucleotides. ${ }^{4,5}$ Conversely, other Zn-DPA-based sensors exhibit their largest fluorescence response in the presence of a particular nucleotide, often ATP $;{ }^{6}$ for such sensors, discrimination between nucleotides can sometimes be effected on the basis of spectroscopic features such as change in ratiometric fluorescence intensities. ${ }^{7}$ However, it should be noted that even for the same sensor, a change in solvent composition can reverse the selectivity between nucleotides. ${ }^{8}$ Zn-DPA-based sensors with selectivity for Adenosine monophosphate (AMP) ${ }^{9}$ and for cyclic phosphates (cAMP, cGMP $)^{10}$ have also been reported. Zn-DPA-based sensors for the various analytes discussed above whose readout is colorimetric (as opposed to fluorescent) have been described. ${ }^{11}$ To our knowledge, the work of Feng and co-workers constitutes the only Zn-DPA-based sensor to date having selectivity for ADP
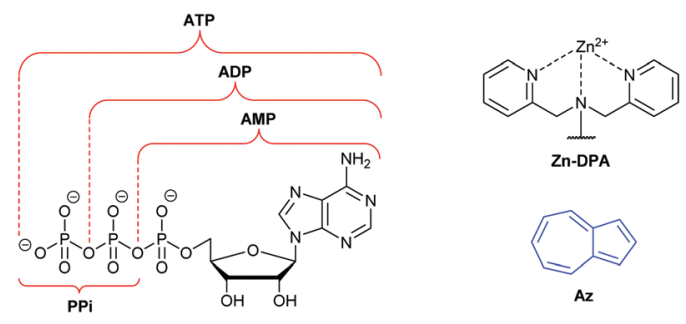

Fig. 1 Structures of adenosine phosphates, zinc-dipicolylamine and azulene. 
over ATP in terms of fluorescence enhancement. ${ }^{12}$ The desirability of methods for the effective discrimination of ATP and ADP specifically has also led to the development of numerous approaches based on sensor designs other than Zn-DPA receptors. ${ }^{13,14}$

Azulene $(\mathrm{Az})$ is a non-benzenoid isomer of the more wellknown naphthalene, from which its properties differ significantly. ${ }^{15}$ The smaller $S_{0}-S_{1}$ energy gap of azulene leads to absorption in the visible region and hence an intense blue colour. Furthermore, it has a large dipole moment of $1.08 \mathrm{D},{ }^{16}$ and azulene and some derivatives are known to exhibit anomalous fluorescence, emitting primarily or entirely from higher excited states, in violation of Kasha's rule. ${ }^{17}$ Substituents on the azulene ring can profoundly alter the absorption and emission spectra, ${ }^{18}$ making an azulene ring a versatile reporter motif for chemosensors and chemodosimeters. Colorimetric azulene probes have been developed for a wide variety of analytes, ${ }^{19}$ whereas fluorescent azulene probes are fewer in number. ${ }^{20,21}$ In this communication we report the design, synthesis, and evaluation of a fluorescent sensor for nucleotides comprising Zn-DPA receptor motifs appended to an azulene reporter motif, which displays selectivity for ADP over ATP.

Our probe design involved connecting two Zn-DPA receptor motifs to the central azulene core (at the 1- and 3-positions) via a $\pi$-conjugated linker. Two isomeric linkers were employed ( $p$-phenylene and $m$-phenylene), giving the two probes $1 \cdot 2 \mathrm{Zn}$ and 2.2Zn (Fig. 2). Details of their synthesis are given in the ESI. $\dagger$ A key aspect of the probe design is that the amine groups of the DPA recognition units are directly conjugated to the fluorophore through the $\pi$-linker, in contrast to most previously reported Zn-DPA containing nucleotide sensors such as Feng's anthracene-containing ADP-selective system. ${ }^{12}$ For both probes, X-ray crystal structures of the unbound ligand forms were obtained and are shown in Fig. 3.

Initially 1 and 2 were treated with $\mathrm{Zn}\left(\mathrm{NO}_{3}\right)_{2}$ and a selection of other metal salts, and absorption spectra were acquired (Fig. S1 and S2, ESI $\dagger$ ). As expected, changes in the absorbance spectra were observed (more pronounced for 2), confirming that complexation of the amine lone pairs results in electronic perturbation of the azulene chromophore. The zinc complexes 1.2Zn and $2 \cdot 2 \mathrm{Zn}$ were then exposed to a selection of anions and absorption spectra again acquired (Fig. S3 and S4, ESI $\dagger$ ). The fluorescence response of the probes to the same anions was then studied (Fig. 4 and Fig. S5, ESI $\dagger$ ). For both probes, a significant fluorescence enhancement is observed in response to ADP, whereas PPi induced a negligible response. Overall,
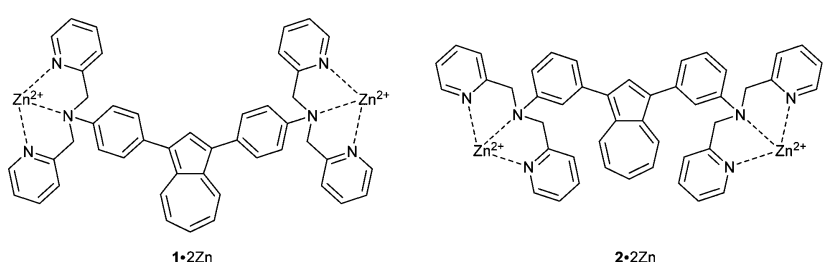

Fig. 2 Structures of probes $1 \cdot 2 \mathrm{Zn}$ and $2 \cdot 2 \mathrm{Zn}$.
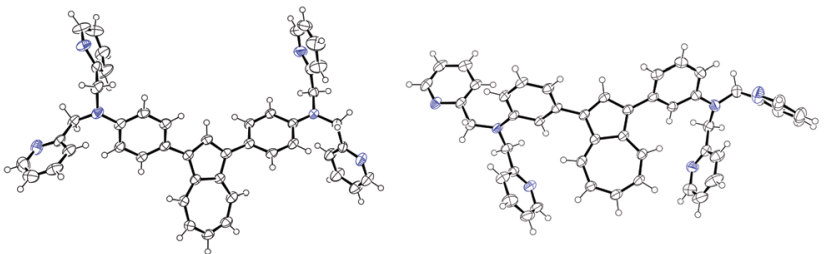

Fig. 3 ORTEP representation of the X-ray structures of 1 (left) and 2 (right). Ellipsoids are shown at $50 \%$ probability. Hydrogens are shown as spheres of arbitrary radius. CCDC $\dagger \# 2095982$ and 2095983.
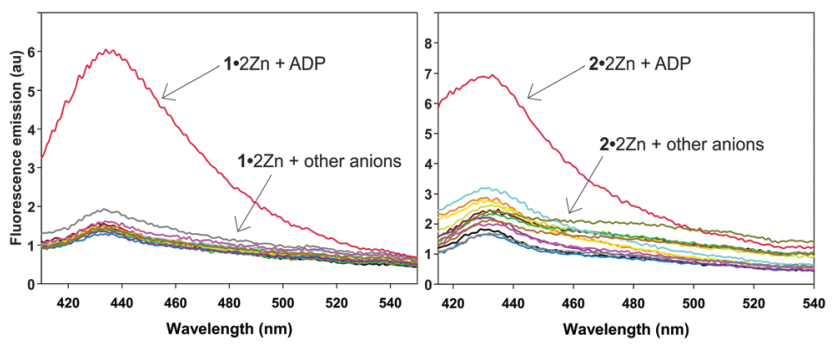

Fig. 4 Fluorescence emission spectra for 1.2Zn (left) and 2.2Zn (right), each $100 \mu \mathrm{M}$, in the presence of $\mathrm{NaF}, \mathrm{NaCl}, \mathrm{NaBr}, \mathrm{Nal}, \mathrm{NaNO}_{3}, \mathrm{Na}_{2} \mathrm{HPO}_{4}$, $\mathrm{Na}_{4} \mathrm{P}_{2} \mathrm{O}_{7}, \mathrm{Na}_{2} \mathrm{SO}_{4}, \mathrm{Na}_{2} \mathrm{CO}_{3}, \mathrm{Na}_{2} \mathrm{HAsO}_{4}$ and $\mathrm{ADP}$ sodium salt (all $1 \mathrm{mM}$ ). Spectra were measured after $30 \mathrm{~min}$. The data were obtained at $25^{\circ} \mathrm{C}$. Fluorescence intensities were measured with $\lambda_{\text {exc }}=380$ (bandwidth 20) nm on a BMG Labtech CLARIOstar plate reader. For $1.2 \mathrm{Zn}$, solvent was HEPES buffer $50 \% \mathrm{H}_{2} \mathrm{O}: 50 \% \mathrm{MeCN}, \mathrm{pH}=7.3$; for $2.2 \mathrm{Zn}$, solvent was HEPES buffer $50 \% \mathrm{H}_{2} \mathrm{O}: 50 \% \mathrm{DMSO}, \mathrm{pH}=7.3$. The $y$-axis shows fluorescence intensity in arbitrary units.

1.2Zn shows the better selectivity profile with respect to the potentially interfering anions that were evaluated. Since both probes possessed selectivity for ADP their responses to other phosphorylation states of this nucleotide were also evaluated (Fig. 5 and Fig. S6, ESI $\dagger$ ).

Here the behaviour of the two probes differed markedly. $2 \cdot 2 \mathrm{Zn}$ was unable to distinguish between ADP and ATP, with both analytes causing fluorescence enhancements of similar

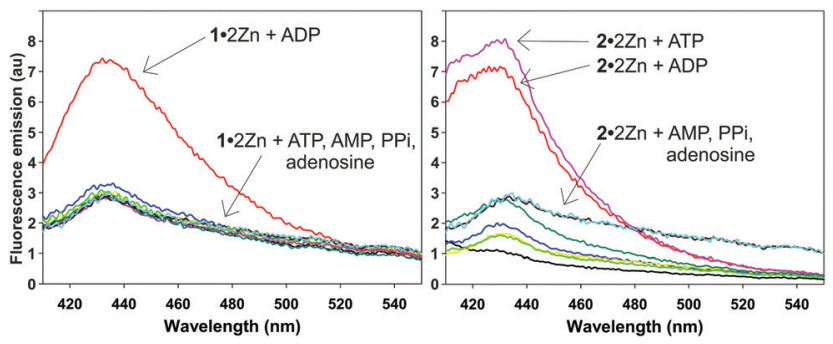

Fig. 5 Fluorescence emission spectra for 1.2Zn (left) and 2.2Zn (right), each $100 \mu \mathrm{M}$, in the presence of $\mathrm{Na}_{2} \mathrm{HPO}_{4}, \mathrm{Na}_{4} \mathrm{P}_{2} \mathrm{O}_{7}, \mathrm{AMP}$ sodium salt, ADP sodium salt, ATP sodium salt and adenosine (all $1 \mathrm{mM}$ ). Spectra were measured after $30 \mathrm{~min}$. The data were obtained at $25^{\circ} \mathrm{C}$. Fluorescence intensities were measured with $\lambda_{\mathrm{exc}}=380$ (bandwidth 20) $\mathrm{nm}$ on a BMG Labtech CLARIOstar plate reader. For 1.2Zn, solvent was HEPES buffer $50 \%$ $\mathrm{H}_{2} \mathrm{O}: 50 \% \mathrm{MeCN}, \mathrm{pH}=7.3$; for $2 \cdot 2 \mathrm{Zn}$, solvent was HEPES buffer $50 \% \mathrm{H}_{2} \mathrm{O}$ : $50 \% \mathrm{DMSO}, \mathrm{pH}=7.3$. The $y$-axis shows fluorescence intensity in arbitrary units. 

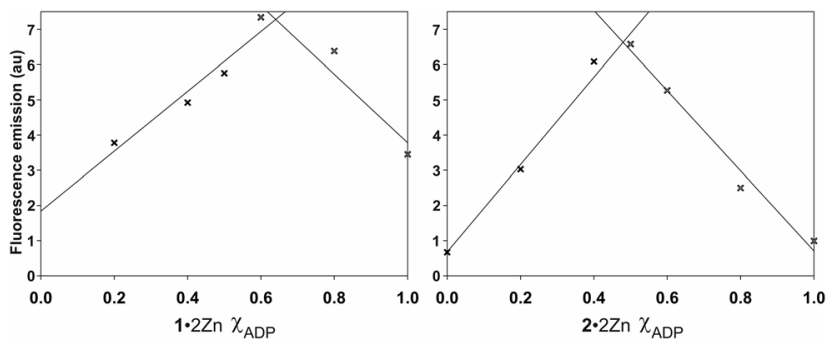

Fig. 6 Job plots for 1.2Zn (left) and 2.2Zn (right), against ADP $(200 \mu \mathrm{M}$ at $\left.\chi_{\text {ADP }}=1\right)$. The data were obtained at $25^{\circ} \mathrm{C}$, at $\lambda_{\text {em }}=435 \mathrm{~nm}$. Fluorescence intensities were measured with $\lambda_{\text {exc }}=380$ (bandwidth 20) nm, on a BMG Labtech CLARIOstar plate reader. The $y$-axis shows fluorescence intensity in arbitrary units.

magnitude. In contrast, however, 1·2Zn displayed pronounced selectivity for ADP over ATP (and AMP), with the latter analytes inducing a near-negligible change in fluorescence over basal levels. We next considered the binding stoichiometry of the two probes with ADP (Fig. 6).

Job plot analysis indicated different stoichiometries of binding for the two probes: whereas $2 \cdot 2 \mathrm{Zn}$ binds ADP in a $1: 1$ ratio, 1.2Zn seemingly binds ADP in a 1:2 ratio; fluorescence doseresponse titrations (Fig. S7 and S8, ESI $\dagger$ ) further support these stoichiometries. We noted that at concentrations above $1 \mathrm{mM}$ 1.2Zn $\subset 2 \mathrm{ADP}$ began to precipitate from solution after standing for $\approx 5$ min (Fig. S9, ESI $\dagger$ ). Formation of a less-soluble complex upon analyte binding (and precipitation at high concentrations) has been reported for other Zn-DPA nucleotide sensors. ${ }^{5 c, 12 a}$ The response of $1 \cdot 2 \mathrm{Zn}$ to other nucleobases was also studied (Fig. S10, ESI $\dagger$ ). To rationalise the stoichiometry of binding and selectivity for ADP of 1.2Zn, we propose the binding mode shown in Fig. 7, namely a nucleobase-fluorophore-nucleobase $\pi$-stacked arrangement. Such an assembly rationalises the relative lack of response to PPi (lack of $\pi$-stacking) as well as to ATP (binding of triphosphate to Zn-DPA would lead to incorrect positioning of the purine ring for $\pi$-stacking). Analogous binding modes have been invoked for other Zn-DPA nucleotide sensors. ${ }^{12 a}$

Two-Photon Microscopy (TPM) cell imaging studies were conducted to confirm the applicability of $\mathbf{1}$ in biological

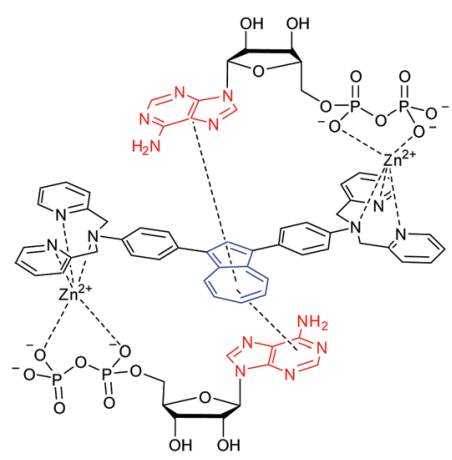

Fig. 7 Proposed binding mode for $1.2 Z n \subset 2 A D P$.
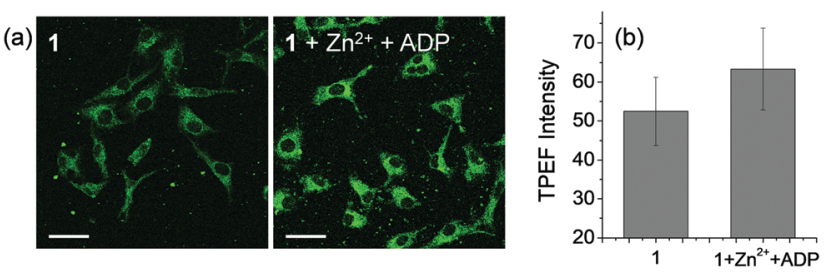

Fig. 8 (a) TPM images of HeLa cells were stained with $1(10 \mu M)$ for 30 min before and after treatment with $\mathrm{Zn}^{2+}(50 \mu \mathrm{M})$ and ADP $(200 \mu \mathrm{M})$. (b) Average fluorescence intensity of corresponding TPM images. Images were obtained at $740 \mathrm{~nm}$ excitation and $400-700 \mathrm{~nm}$ detection windows. Scale bars $=50 \mu \mathrm{m}$.

systems. First, to determine the appropriate two-photon excitation wavelength of the probe, two-photon excited fluorescence (TPEF) intensities were observed using HeLa cells stained with $\mathbf{1}(10 \mu \mathrm{M})$ (Fig. S11, ESI $\dagger$ ). The TPEF intensity of $\mathbf{1}$ increased up to $740 \mathrm{~nm}$ excitation wavelength and gradually weakened with subsequent increases in wavelength, so we set the appropriate two-photon excitation wavelength of this probe at $740 \mathrm{~nm}$. Next, we observed changes of TPEF intensity on treatment with $\mathrm{Zn}^{2+}$ $(50 \mu \mathrm{M})$ and ADP $(200 \mu \mathrm{M})$ in HeLa cells to confirm that 1 can detect ADP in living cells. As a result of treating HeLa cells with $\mathrm{Zn}^{2+}$ and ADP, the TPEF intensity of cells stained with $\mathbf{1}$ was observed to increase (Fig. 8). Cell viability assays (Fig. S12, ESI $\dagger$ ) showed no significant cytotoxicity upon incubation of the cells with $1, \mathrm{Zn}^{2+}$ and ADP at the concentrations specified above. These results indicate that $1 \cdot 2 \mathrm{Zn}$ can directly detect the presence of ADP in biological systems.

In summary, we disclose the first azulene-based fluorescent chemosensor for nucleotides $(\mathbf{1} \cdot 2 \mathrm{Zn})$, which we have named "AzuFluor ${ }^{\circledR}$ 435-DPA-Zn", and which is selective for ADP over other phosphorylation states of adenosine. The receptor motif(s) employed (zinc(II)-dipicolylamine chelates) can exhibit differing selectivity profiles for various phosphate analytes, dependent on the structure of the probe in question. Thus, in the case of $1.2 \mathrm{Zn}$ we surmise that the selectivity for ADP is a consequence of the particular arrangement of the receptor motifs, which in turn arises from the use of the $p$-phenylene linker and the attachment at the azulene 1- and 3-positions. This conclusion is supported by the fact that changing the

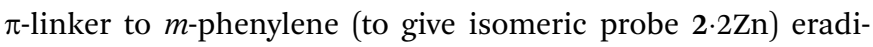
cates the system's ability to discriminate between ADP and ATP.

We thank EPSRC for IAA funding (EP/R51164X/1) and for DTG $\mathrm{PhD}$ studentships to L. C. M. and J. L. H. We are grateful for PhD funding to C. M. L.-A. from the EU Horizon 2020 research and innovation programme under grant agreement H2020-MSCA-COFUND, \#665992. T. D. J. wishes to thank the Royal Society for a Wolfson Research Merit Award and the Open Research Fund of the School of Chemistry and Chemical Engineering, Henan Normal University for support (2020ZD01). The British-Spanish Society and Plastic Energy are thanked for a 2017 Scholarship to C.M.L.-A. The authors acknowledge the Material and Chemical Characterisation Facility $\left(\mathrm{MC}^{2}\right)$ at University of Bath (doi:10.15125/mx6j-3r54). H. M. $\mathrm{K}$. acknowledges the grants from the National Research Foundation of Korea (2019R1A2B5B03100278 and 2019R1A5A2026045). 


\section{Conflicts of interest}

The trademark "AzuFluor ${ }^{\mathbb{B}}$ ", is registered to the University of Bath, which may benefit financially from sales of AzuFluor 435-DPA-Zn.

\section{References}

1 For reviews, see: (a) A. Nag and S. Das, Isr. J. Chem., 2021, 61, 169-184; (b) P. Sun, H. Zhang, Y. Sun and J. Liu, Spectrochim. Acta, Part A, 2021, 245, 118919; (c) W. Li, X. Gong, X. Fan, S. Yin, D. Su, X. Zhang and L. Yuan, Chin. Chem. Lett., 2019, 30, 1775-1790; (d) A. M. Agafontsev, A. Ravi, T. A. Shumilova, A. S. Oshchepkov and E. A. Kataev, Chem. - Eur. J., 2019, 25, 2684-2694; (e) Y. Zhou, Z. Xu and J. Yoon, Chem. Soc. Rev., 2011, 40, 2222-2235.

2 For reviews, see: $(a)$ Y. W. Jun, S. Sarkar, K. H. Kim and K. H. Ahn, ChemPhotoChem, 2019, 3, 214-219; (b) Y. Wu, J. Wen, H. Li, S. Sun and Y. Xu, Chin. Chem. Lett., 2017, 28, 1916-1924; (c) J. Dong and M. Zhao, TrAC, Trends Anal. Chem., 2016, 80, 190-203.

3 For a review, see: H. T. Ngo, X. Liu and K. A. Jolliffe, Chem. Soc. Rev., 2012, 41, 4928-4965.

4 For reviews, see: (a) S. Lee, K. K. Y. Yuen, K. A. Jolliffe and J. Yoon, Chem. Soc. Rev., 2015, 44, 1749-1762; (b) S. Anbu, A. Paul, G. J. Stasiuk and A. J. L. Pombeiro, Coord. Chem. Rev., 2021, 431, 213744.

5 For selected examples, see: (a) S. Yang, W. Feng and G. Feng, Anal. Chim. Acta, 2018, 1034, 119-127; (b) X. Liu, D. G. Smith and K. A. Jolliffe, Chem. Commun., 2016, 52, 8463-8466; (c) S.-Y. Jiao, K. Li, X. Wang, Z. Huang, L. Pu and X.-Q. Yu, Analyst, 2015, 140, 174-181; (d) S. Anbu, S. Kamalraj, A. Paul, C. Jayabaskaran and A. J. L. Pombeiro, Dalton Trans., 2015, 44, 3930-3933; (e) V. E. Zwicker, B. M. Long and K. A. Jolliffe, Org. Biomol. Chem., 2015, 13, 7822-7829; $(f)$ L. Tang, Z. Zheng, Z. Huang, K. Zhong, Y. Bian and R. Nandhakumar, RSC Adv., 2015, 5, 10505-10511; (g) J. Wang, X. Liu and Y. Pang, J. Mater. Chem. B, 2014, 2, 6634-6638; (h) F. Huang and G. Feng, RSC Adv., 2014, 4, 484-487; (i) S.-i. Kondo, Y. Nakadai and M. Unno, RSC Adv., 2014, 4, 27140-27145; (j) Q.-C. Xu, X.-F. Wang, G.-W. Xing and Y. Zhang, $R S C$ Adv., 2013, 3, 15834-15841; (k) X. Liu, H. T. Ngo, Z. Ge, S. J. Butler and K. A. Jolliffe, Chem. Sci., 2013, 4, 1680-1686; (l) L. G. Pathberiya, N. Barlow, T. Nguyen, B. Graham and K. L. Tuck, Tetrahedron, 2012, 68, 9435-9439; $(m)$ J. H. Lee, A. R. Jeong, J.-H. Jung, C.-M. Park and J.-I. Hong, J. Org. Chem., 2011, 76, 417-423; (n) W.-H. Chen, Y. Xing and Y. Pang, Org. Lett., 2011, 13, 1362-1365; (o) J. F. Zhang, S. Kim, J. H. Han, S.-J. Lee, T. Pradhan, Q. Y. Cao, S. J. Lee, C. Kang and J. S. Kim, Org. Lett., 2011, 13, 5294-5297; (p) J. Veliscek-Carolan, S. J. Butler and K. A. Jolliffe, J. Org. Chem., 2009, 74, 2992-2996; (q) M. J. McDonough, A. J. Reynolds, W. Y. G. Lee and K. A. Jolliffe, Chem. Commun., 2006, 2971-2973; (r) H. N. Lee, Z. Xu, S. K. Kim, K. M. K. Swamy, Y. Kim, S.-J. Kim and J. Yoon, J. Am. Chem. Soc., 2007, 129, 3828-3829; (s) D. H. Lee, S. Y. Kim and J.-I. Hong, Angew. Chem., Int. Ed., 2004, 43, 4777-4780.

6 (a) Y. Kurishita, T. Kohira, A. Ojida and I. Hamachi, J. Am. Chem. Soc., 2012, 134, 18779-18789; (b) A. Ojida, I. Takashima, T. Kohira, H. Nonaka and I. Hamachi, J. Am. Chem. Soc., 2008, 130, 12095-12101; (c) A. Ojida, Y. Miyahara, J. Wongkongkatep, S.-I. Tamaru, K. Sada and I. Hamachi, Chem. - Asian J., 2006, 1, 555-563; (d) A. Ojida, H. Nonaka, Y. Miyahara, S.-I. Tamaru, K. Sada and I. Hamachi, Angew. Chem., Int. Ed., 2006, 45, 5518-5521; (e) A. Ojida, S.-K. Park, Y. Mito-oka and I. Hamachi, Tetrahedron Lett., 2002, 43, 6193-6195.

7 (a) J. Kim, J. Oh and M. S. Han, RSC Adv., 2021, 11, 10375-10380; (b) Q.-C. Xu, H.-J. Lv, Z.-Q. Lv, M. Liu, Y.-J. Li, X.-F. Wang, Y. Zhang and G.-W. Xing, RSC Adv., 2014, 4, 47788-47792; (c) Z. Xu, D. R. Spring and J. Yoon, Chem. - Asian J., 2011, 6, 2114-2122.

8 S. Marbumrung, K. Wongravee, V. Ruangpornvisuti, G. Tumcharern, T. Tuntulani and B. Tomapatanaget, Sens. Actuators, B, 2012, 171-172, 969-975.

9 L. Reinke, M. Koch, C. Müller-Rennoc and S. Kubik, Org. Biomol. Chem., 2021, 19, 3893-3900.

10 D. S. Philips, S. Ghosh, K. V. Sudheesh, C. H. Suresh and A. Ajayaghosh, Chem. - Eur. J., 2017, 23, 17973-17980.
11 (a) S. Minagawa, S. Fujiwara, T. Hashimoto and T. Hayashita, Int. J. Mol. Sci., 2021, 22, 4683; (b) S. Yang, G. Feng and N. H. Williams, Org. Biomol. Chem., 2012, 10, 5606-5612; (c) F. Huang, C. Cheng and G. Feng, J. Org. Chem., 2012, 77, 11405-11408; (d) K. M. Kim, D. J. Oh and K. H. Ahn, Chem. - Asian J., 2011, 6, 122-127; (e) D. H. Lee, J. H. Im, S. U. Son, Y. K. Chung and J.-I. Hong, J. Am. Chem. Soc., 2003, 125, 7752-7753.

12 (a) F. Huang, G. Hao, F. Wu and G. Feng, Analyst, 2015, 140, 5873-5876; (b) P. Hu, S. Yang and G. Feng, Org. Biomol. Chem., 2014, 12, 3701-3706; (c) L. Shi, P. Hu, Y. Ren and G. Feng, Chem. Commun., 2013, 49, 11704-11706.

13 For a review, see: S. J. Butler and K. A. Jolliffe, ChemPlusChem, 2021, 86, 59-70.

14 For selected examples, see: (a) S. Nakano, M. Shimizu, H. Dinh and T. Morii, Chem. Commun., 2019, 55, 1611-1614; (b) A. Kumar, P. Prasher and P. Singh, Org. Biomol. Chem., 2014, 12, 3071-3079; (c) K. Ghosh and I. Saha, Org. Biomol. Chem., 2012, 10, 9383-9392; (d) S. Kunzelmann and M. R. Webb, ACS Chem. Biol., 2010, 5, 415-425; (e) D. Wang, X. Zhang, C. He and C. Duan, Org. Biomol. Chem., 2010, 8, 2923-2925; $(f)$ S. Kunzelmann and M. R. Webb, J. Biol. Chem., 2009, 284, 33130-33138; $(g)$ K. M. Kleman-Leyer, T. A. Klink, A. L. Kopp, T. A. Westermeyer, M. D. Koeff, B. R. Larson, T. J. Worzella, C. A. Pinchard, S. A. T. van de Kar, G. J. R. Zaman, J. J. Hornberg and R. G. Lowery, Assay Drug Dev. Technol., 2009, 7, 56-67; (h) L. Vial and P. Dumy, J. Am. Chem. Soc., 2007, 129, 4884-4885; ( $i$ ) S. Litvinchuk, N. Sordé and S. Matile, J. Am. Chem. Soc., 2005, 127, 9316-9317; $(j)$ J. Srinivasan, S. T. Cload, N. Hamaguchi, J. Kurz, S. Keene, M. Kurz, R. M. Boomer, J. Blanchard, D. Epstein, C. Wilson and J. L. Diener, Chem. Biol., 2004, 11, 499-508; $(k)$ M. Brune, J. E. T. Corrie and M. R. Webb, Biochemistry, 2001, 40, 5087-5094.

15 R. S. H. Liu, J. Chem. Educ., 2002, 79, 183.

16 A. G. Anderson Jr. and B. M. Steckler, J. Am. Chem. Soc., 1959, 81, 4941.

17 (a) M. Beer and H. C. Longuet-Higgins, J. Chem. Phys., 1955, 23, 1390; (b) B. D. Wagner, D. Tittelbach-Helmrich and R. P. Steer, J. Phys. Chem., 1992, 96, 7904; (c) K. Veys and D. Escudero, J. Phys. Chem. A, 2020, 124, 7228.

18 R. S. H. Liu, R. S. Muthyala, X.-S. Wang and A. E. Asato, Org. Lett., 2000, 2, 269-271.

19 For selected examples, see: (a) Y. Jin, K. Akagawa, T. Mutai, I. Yoshikawa and K. Kudo, Tetrahedron, 2021, 88, 132146; (b) H. Xin, J. Li, X. Yang and X. Gao, J. Org. Chem., 2020, 85, 70; (c) L. C. Murfin, C. M. López-Alled, A. C. Segwick, J. Wenk, T. D. James and S. E. Lewis, Front. Chem. Sci. Eng., 2020, 14, 90; (d) C. M. López-Alled, L. C. Murfin, G. Kociok-Köhn, T. D. James, J. Wenk and S. E. Lewis, Analyst, 2020, 145, 6262; $(e)$ L. C. Murfin, K. Chiang, G. T. Williams, C. L. Lyall, A. T. A. Jenkins, J. Wenk, T. D. James and S. E. Lewis, Front. Chem., 2020, 8, 10; $(f)$ H. Xin, J. Li, X. Yang and X. Gao, J. Org. Chem., 2019, 85, 70; $(g)$ D. Lichosyt, S. Wasiłek, P. Dydio and J. Jurczak, Chem. - Eur. J., 2018, 24, 11683; (h) G.-O. Buica, I.-G. Lazar, L. Birzan, C. Lete, M. Prodana, M. Enachescu, V. Tecuceanu, A. B. Stoian and E.-M. Ungureanu, Electrochim. Acta, 2018, 263, 382; (i) C. M. López-Alled, A. SanchezFernandez, K. J. Edler, A. C. Sedgwick, S. D. Bull, C. L. McMullin, G. Kociok-Köhn, T. D. James, J. Wenk and S. E. Lewis, Chem. Commun., 2017, 53, 12580; $(j)$ L. Birzan, M. Cristea, C. C. Draghici, V. Tecuceanu, M. Maganu, A. Hanganu, G.-L. Arnold, E.-M. Ungureanu and A. C. Razus, Tetrahedron, 2016, 72, 2316; (k) S. Wakabayashi, M. Uchida, R. Tanaka, Y. Habata and M. Shimizu, Asian J. Org. Chem., 2013, 2, 786.

20 For a review, see: L. C. Murfin and S. E. Lewis, Molecules, 2021, 26, 353.

21 For selected examples, see: (a) L. C. Murfin, M. Weber, S. J. Park, W. T. Kim, C. M. Lopez-Alled, C. L. McMullin, F. Pradaux-Caggiano, C. L. Lyall, G. Kociok-Köhn, J. Wenk, S. D. Bull, J. Yoon, H. M. Kim, T. D. James and S. E. Lewis, J. Am. Chem. Soc., 2019, 141, 19389; (b) Y. Zhou, G. Baryshnikov, X. Li, M. Zhu, H. Ågren and L. Zhu, Chem. Mater., 2018, 30, 8008; (c) P. M. Gosavi, Y. S. Moroz and I. V. Korendovych, Chem. Commun., 2015, 51, 5347; (d) Y. S. Moroz, W. Binder, P. Nygren, G. A. Caputo and I. V. Korendovych, Chem. Commun., 2013, 49, 490; (e) H. Salman, Y. Abraham, S. Tal, S. Meltzman, M. Kapon, N. Tessler, S. Speiser and Y. Eichen, Eur. J. Org. Chem., 2005, 2207. 